\title{
Determinants of HIV-risk sexual behaviors among Zambian adolescents: The role of gendered power
}

\author{
Sherinah K. Saasa \\ Brigham Young University - Provo, sherinah_saasa@byu.edu \\ Orion Mowbray \\ University of Georgia
}

Follow this and additional works at: https://scholarsarchive.byu.edu/facpub

Part of the Social Work Commons

\section{Original Publication Citation}

Saasa, S. K., \& Mowbray, O. (published online Aug 2019). Determinants of HIV-risk sexual behaviors among Zambian adolescents: The role of gendered power. Children and Youth Services Review, 104484.

\section{BYU ScholarsArchive Citation}

Saasa, Sherinah K. and Mowbray, Orion, "Determinants of HIV-risk sexual behaviors among Zambian adolescents: The role of gendered power" (2019). Faculty Publications. 4114.

https://scholarsarchive.byu.edu/facpub/4114 


\title{
Determinants of HIV-risk sexual behaviors among Zambian adolescents: The role of gendered power
}

\author{
Sherinah K. Saasa ${ }^{\mathrm{a}, *}$, Orion Mowbray ${ }^{\mathrm{b}}$

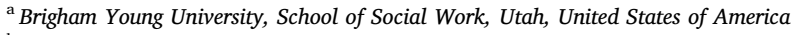 \\ ${ }^{\mathrm{b}}$ University of Georgia, School of Social Work, Georgia, United States of America
}

\section{A R T I C L E I N F O}

\section{Keywords:}

Adolescents

Gender

Power

Social dominance theory

Zambia

Sexual behavior

\begin{abstract}
A B S T R A C T
Sub-Saharan African adolescents account for a disproportionate share of the global HIV infection rates with adolescent females carrying the heavy burden. Vulnerability to negative sexual health outcomes have been attributed to varying life contexts and power differentials influencing adolescent sexual behaviors. Using social dominance theory and the four bases of gendered power, this study examines the relationship between gender based power and adolescent HIV-risk sexual behavior. Data was derived from the 2013-14 Zambia Demographic Health Survey (ZDHS). We utilize gender stratified multivariate logistic regression to determine whether the four bases of gendered power are predictive of condom use and multiple sexual partnering among sexually active adolescents $(\mathrm{N}=1908)$, ages 15-19. Findings highlight the significant effects of sexual abuse, resource constraints (low levels of education, condom access, poverty) and gender-unequal beliefs and values on the odds of adolescent HIV-risk sexual behavior. We found gender variant effects of these factors on sexual behavior. For males, beliefs in gender-unequal norms acted as a barrier to condom use. Among females, having no education facilitated multiple sexual partnering. Implications for policy and practice are provided.
\end{abstract}

\section{Introduction}

In 2018, Sub-Saharan Africa accounted for $89 \%$ of adolescents living with HIV worldwide with adolescent girls being newly infected with HIV at four times the rate of adolescent boys (UNICEF, 2019). Acquired Immunodeficiency Syndrome (AIDS) has also become the leading cause of death among this group (Fleischman \& Peck, 2015). In addition high poverty rates, Zambia is heavily affected by the HIV/AIDS pandemic with a national HIV prevalence at approximately $11.3 \%$ in 2018 and approximately 17, 000 AIDS-related deaths (UNAIDS, 2019; World Bank, 2019). The Zambian HIV epidemic is largely driven by unprotected heterosexual sex, with higher rates of new infections resulting from low and inconsistent condom use. For instance, less than half of youth endorsed condom use at their last sexual encounter with a non-marital or cohabiting partner in 2014 (Central Statistical Office (CSO) [Zambia], Ministry of Health (MOH) [Zambia], and ICF International, 2014).

Efforts to turn the tide on HIV/AIDS in Zambia have increasingly focused on youth and adolescent services (UNAIDS, 2019). This is vital for the nation's future economic and health outcomes given it's young populace, 66\% under age 24 in 2014 (Central Statistical Office (CSO) [Zambia], Ministry of Health (MOH) [Zambia], and ICF International,
2014). HIV prevalence among Zambian young women was more than double that of young men ( $5 \%$ of girls, compared to $2.4 \%$ boys) in 2018 (UNAIDS, 2019). Alongside increased biological vulnerability to HIV infection, contextual factors such as age-disparate relationships, sexual violence, poverty, and limited sexual decision making power have been found to increase young women's risk for HIV infection (Butts et al., 2017a; Ott, Barnighausen, Tanser, Lurie, \& Newell, 2011; Jewkes, Dunkle, Nduna, \& Shai, 2012;). With heterosexual contact accounting for the majority of HIV infection in women (Central Statistical Office (CSO) [Zambia], Ministry of Health ( $\mathrm{MOH})$ [Zambia], and ICF International, 2014), scholars highlight the role of power in gender variant sexual risk behavior (Butts et al., 2017; Conroy, 2015; Rosenthal \& Levy, 2010; Svanemyr, 2019).

Research examining individual and environmental factors associated with adolescent HIV risk in Sub-Saharan Africa is expanding (Amoateng, Kalule-Sabiti, \& Arkaah, 2014; Butts et al., 2017; ChandaKapata, Klinkenberg, Maddox, Ngosa, \& Kapata, 2016; Cluver, Orkin, Meinck, Boyes, \& Sherr, 2016; Gyimah, Kodzi, Emina, Adjei, \& Ezeh, 2014; John, Okolo, \& Isichei, 2014; Lightfoot, Maree, \& Ananias, 2009; Magadi \& Uchudi, 2015; Operario, Underhill, Chuong, \& Cluver, 2011; Toska et al., 2017). However, few studies explicitly examine the intersection of gendered power and adolescent HIV risk behaviors in

\footnotetext{
* Corresponding author at: Brigham Young University, School of Social Work, 2190 JFSB, Provo, UT 84604, United States of America.

E-mail address: sherinah_saasa@byu.edu (S.K. Saasa).
} 
Zambia; a gap this study hopes to address. Understanding mechanisms that facilitate and maintain the disproportionate HIV risk among male and female adolescents and how this can be halted is vital. Therefore, the aim of this study was to contribute to the understanding of how factors of gender-based power influence HIV-risk sexual behaviors, conceptualized in this study as the occurrence of unprotected sex and multiple sexual partnering, among Zambian adolescents.

\section{Theoretical perspective and review of literature}

\subsection{Social dominance theory and the four bases of gendered power}

To provide a unique perspective on the issue of gender and hiv-risk sexual behavior, this study utilizes social dominance theory (SDT) with particular attention to the four bases of gendered power (Pratto \& Walker, 2004; Sidanius \& Pratto, 1999). This theory focuses on individual and structural factors that facilitate varied forms of groupbased oppression. SDT posits that disadvantaged groups experience interpersonal and institutional discrimination due to societal hierarchies that are based on social categories such as race, class and gender (Sidanius \& Pratto, 1999; Sidanius, Pratto, van Laar, \& Levin, 2004).

Social dominance theory identifies four bases of gendered power that operate on individual, group, institutional and structural levels: force, resource control, social obligations and consensual ideologies (Pratto \& Walker, 2004). This theory proposes that gendered forms of power help to maintain the disproportionate HIV risk among adolescent females compared to males. Within the context of sexual behaviors, power has been referred to as the ability to act independently and ability to influence the actions of others (Pulerwitz, Gortmaker, \& DeJong, 2000; Wingood \& DiClemente, 2000).

Pratto and Walker (2004) identified force, which includes assault, rape, sexual harassment, emotional abuse and other forms of violence, as the first base of gendered power due to it's significant role in maintaining hierarchical power between men and women. Evidence shows that childhood sexual abuse is associated with adolescents' HIVrisk behaviors, including lower condom use and higher incidence of multiple sexual partnering and HIV infection (Jewkes, Dunkle, Nduna, Jama, \& Puren, 2010; Ministry of Youth, Sport and Child Development [MYSCD], 2018; Slonim-Nevo \& Mukuka, 2007). In 2014, Zambia's national estimates on sexual violence in childhood showed that about $20 \%$ of females and $10 \%$ of males between ages 18-24 had experienced childhood sexual violence, while about $17 \%$ of females and $6 \%$ of males aged 13-17 years were sexually abused within the previous year (MYSCD, 2018). These high rates of sexual violence create significant sources of HIV risk with adolescent girls experiencing the larger burden.

Resource control entails mechanisms that facilitate coordinated discrimination in resource allocation by social institutions (e.g. schools, health care, job allocation, marital or relational practices) in ways that generally advantage men while facilitating undesirable outcomes for women (Pratto \& Walker, 2004; Rosenthal \& Levy, 2010; Sidanius et al., 2004). Research among sub-Saharan African adolescents indicates that poverty, education, economic dependence on men and transactional sex are associated with women's increased HIV risk (Gyimah et al., 2014; Jukes, Simmons, \& Bundy, 2008; Madise, Zulu, \& Ciera, 2007; Muzyamba, Broaddus, \& Campbell, 2015; Ranganathan et al., 2016; Wamoyi et al., 2014). For example, Zambia has more females than males with no formal education, and men are twice as likely to complete secondary school (Central Statistical Office (CSO) [Zambia], Ministry of Health (MOH) [Zambia], and ICF International, 2014). Thus gender inequality in education undermines the potentially protective nature of higher levels of education that have been found to ameliorate HIV risk behaviors (e.g. condom use, age disparate sex and multiple sexual partnering) among sub-Saharan African adolescents (Birdthistle et al., 2009; Doyle, Mavedzenge, Plummer, \& Ross, 2012; Hargreaves et al., 2008; Magnani et al., 2002; Stephenson, 2009). Additionally, adolescent females have reported reduced hiv-related knowledge (e.g. hiv prevention and acquisition, female condom use, where to access condoms) compared to males (Butts et al., 2018; Central Statistical Office (CSO) [Zambia], Ministry of Health (MOH) [Zambia], and ICF International, 2014). Further, economic pressures facilitate greater vulnerability for younger women to engage in sexual relations with much older men (Butts et al., 2017; Doyle et al., 2012; Luke, 2005). Both of these factors limit young women's power to negotiate condom use.

Social obligations, the third base of gendered power, focuses on relationships or care responsibilities where women are more obligated than men to care giving or satisfying others' needs (Pratto \& Walker, 2004). Evidence among young people in sub-Saharan African shows lesser odds of condom use for youth in more committed relationships (Saasa, Choi \& Nackerud, 2018; Burgard \& Kusunoki, 2009; Hendriksen, Pettifor, Lee, Coates, \& Rees, 2007), especially among females. This link between level of relationship commitment and sexual risk raises concerns especially in cultural contexts where male partners may not be monogamous. For instance, social obligations may play a role in the higher rates of HIV infection found among married adolescent girls and women compared to their non-married counterparts (Central Statistical Office (CSO) [Zambia], Ministry of Health (MOH) [Zambia], and ICF International, 2014; Clark, Bruce \& Dude, 2006; Hirsch, Wardlow, \& Smith, 2009; Smith, 2007).

Social dominance theory also proposes that the systemic nature of group discrimination is driven by acceptance of social ideologies and behaviors that legitimize and produce inequality (Sidanius et al., 2004). The fourth base of gendered power, consensual ideologies, refers to beliefs or expectations that undermine women's positions in comparison to men, such as norms, gender roles and stereotypes (Pratto \& Walker, 2004). These ideologies are often accepted by women themselves and contribute to their vulnerability and reduced power to protect themselves from HIV infection (Rosenthal \& Levy, 2010). For example, studies show that women's limited power in relationships is driven by Zambia's extremely patriarchal culture that promotes women's' submissiveness to males from a young age, encourages multiple sexual partnership among males, and sexual scripts that include never refusing sex with husbands regardless of his infidelity or refusal to use condoms (Authors own, 2018; Butts et al., 2017; Joffe \& Bettega, 2003). These ideologies can pause challenges for young women to negotiate safer sex as well as facilitate risky sexual behaviors among young men.

\subsection{Aims of the study}

Social dominance theory, as discussed previously, therefore not only helps us elucidate the relationship between power and the disproportionate rates of heterosexual HIV infection among adolescent girls in Zambia, but it can also highlight how these four bases of gendered power can contribute to hiv-risk among male adolescents (Rosenthal \& Levy, 2010). In this light, the present study examines the impact of the four bases of gendered power on condom use and multiple sexual partnering among adolescents in Zambia. Based on the literature and social dominance theory, the study hypothesized the following: (1)Adolescents with a history of forced sex will have increased likelihood for higher risk sexual behaviors; (2)Adolescents with low levels of education and limited access to condoms will have increased likelihood for higher risk sexual behaviors.; (3) Adolescents in more committed relationships with their last sexual partner will have higher risk for unprotected sex, and low risk for multiple sexual partners, especially among females and, (4)Adolescents that endorse values that place women in subordinate positions relative to men will have increased likelihood for higher risk sexual behaviors. 


\section{Methods}

\subsection{Sample}

This study utilized data from the 2013-2014 Zambia Demographic Health Survey (ZDHS). The ZDHS is a nationally representative crosssectional survey designed to provide data to monitor the population and health situation in Zambia and provide estimates at the national and provincial levels. It contains reliable information on demographic factors as well as HIV knowledge and sexual behaviors of Zambian men ages 15-59 and women ages 15-49. The ZDHS used a two-stage stratified cluster sample design. During the first stage,722 geographical locations (referred to as enumeration areas) with an average size of 130 households were selected. An average of 25 households were selected in each enumeration area during the second stage resulting in the selection of a final representative sample of 18,052 households. A much detailed description of the survey design and sampling procedure is provided in the Zambia report of the ZDHS (Central Statistical Office (CSO) [Zambia], Ministry of Health (MOH) [Zambia], and ICF International, 2014). We utilized estimation methods on all analyses to account for the sampling design of the ZDHS survey (Croft, Marshall, \& Allen, 2018). Our sample consisted of 2298 adolescents between the ages of 15-19 who had at least one sexual encounter. Only adolescents that indicated that they were not married, had been sexually active in the past 12 months, and had no missing data on the dependent variables were included in the study. Therefore, the final sample consisted of about 2124 adolescents.

\subsection{Measures}

\subsubsection{Dependent variables}

Condom use and multiple sexual partnering were examined as two binary outcomes of interest to measure sexual behaviors in the past 12 months. Respondents indicated whether a condom was used at last sexual encounter with their most recent partner (no $=0$, yes $=1$ ). Multiple sexual partnering was derived from a continuous measure asking for the number of sexual partners in the past 12 months. In this sample, the distribution of responses was skewed and ranged from 1 to 11 (about $97 \%$ of participants reported between 1 and 3 sexual partners). Thus this item was recoded into a binary measure as follows: $0=$ one sexual partner, $1=$ two or more past year partners.

\subsubsection{Independent variables}

3.2.2.1. Force. A question examining history of sexual abuse was used for this measure. Participants provided a yes/no response to whether they had ever been forced to have sexual intercourse or perform any other sexual acts against their will. In the ZDHS survey, one eligible woman in each household was selected for the subsample that was asked additional questions on domestic violence from which this question was derived. Thus this measure was not assessed among our male participants in this study. From our sample of 784 female adolescents, only 380 were selected to participate in the domestic violence questionnaire.

3.2.2.2. Resource control. Two aspects of resource control were examined; education level and access to condoms. Highest education level attained was derived from a categorical measure with the following responses (no education, primary, and secondary education or higher). To measure condom access, respondents answered a yes/no question about whether they knew of any source from which they could obtain condoms.

3.2.2.3. Social obligations. Level of relationship commitment with last sexual partner was examined. This measure was derived from a question asking participants what their relationship was with the person they most recently had sexual intercourse with within the past
12 months. Responses included live-in partner, boyfriend not living with respondent, casual acquaintance, other. This item was recoded into a binary measure with responses 'boyfriend' and 'live-in partner' combined into committed relationship $=0$, and all other responses into non-committed relationship $=1$.

3.2.2.4. Consensual ideologies. This measure was derived from 5 questions asking participants if a beating was justified if; wife goes out without telling husband, wife neglects the children, wife argues with husband, wife refuses to have sex with husband, and if wife burns the food. A 'yes' response to any of the 5 items was coded as 1 , and 'no' response $=0$.

\subsubsection{Control variables}

Potential confounders for HIV risk behavior were assessed. These included age (in years), gender, urban/rural residence, household wealth and age of most recent sexual partner. The household wealth index, a composite measure of a household's cumulative living standard, was calculated using data on a household's ownership of selected assets, such as televisions and bicycles; materials used for housing construction; and types of water access and sanitation facilities. This measure placed individual households on a continuous scale of relative wealth and separated all interviewed households into five wealth quintiles: poorest, poor, middle, rich and richer (Central Statistical Office (CSO) [Zambia], Ministry of Health (MOH) [Zambia], and ICF International, 2014). In our analyses, household wealth was recoded into three mutually exclusive categories for easier interpretation (poor, middle, rich). Age of most recent sexual partner was derived from a categorical variable with the following age ranges; 10-14, 15-19, $20-25$, and 26 years old and over.

\subsubsection{Analytic approach}

Sample weights were utilized on all analyses using SPSS version 25. To explore characteristics of the sample, univariate analyses were performed while bivariate and logistic regression analyses were conducted to examine relationships between the four bases of gendered and sexual behavior outcomes. Chi-square tests were used to make comparisons between male and females on key variables and associations between categorical variables and sexual behaviors. Four separate regression analyses for each outcome were conducted. The first model included both male and female adolescents as the sample, the second model included only male participants, and two separate models for females only were conducted (one identical to the male model, and the other included sexual abuse). This allowed us to examine gendered variations in predictors of sexual behavior outcomes. Diagnostics for analytic assumptions were all within acceptable range and no assumptions were violated. All models were controlled for Zambian provinces.

\section{Results}

\subsection{Descriptive statistics}

A summary of descriptive statistics for all study variables and bivariate analysis between condom use and each independent variable for the overall sample are presented in Table 1 . The mean age of the sample was $17.3(\mathrm{SD}=1.68)$, and approximately $61 \%$ identified as male. A small number of participants $(2.7 \%)$ reported having no formal education. About $59 \%$ of the sample reported not using a condom, with only $39 \%$ of females and $42 \%$ of males reporting condom use during their last sexual act. Approximately 14\% of the participants had multiple sexual partners in the past 12 months, of these $62 \%$ did not use a condom at last sexual encounter.

Group differences on study variables between males and females were also examined (results not shown). We found gendered differences in multiple sexual partnering tendencies with higher rates among 
Table 1

Sample characteristics and bivariate associations with sexual behavior.

\begin{tabular}{|c|c|c|c|c|c|}
\hline \multirow[t]{2}{*}{ Variable } & Overall sample $(n=2124)$ & Male $(\mathrm{n}=1288)$ & Female $(n=836)$ & Condom use & Multiple sexual partners \\
\hline & \multicolumn{3}{|l|}{$\%$ or mean $(\mathrm{SD})$} & $\chi^{2}$ & $\chi^{2}$ \\
\hline Gender & & & & 1.1 & $70.7^{* *}$ \\
\hline Male & 60.7 & & & & \\
\hline Female & 39.3 & & & & \\
\hline Age & $17.31(1.68)$ & $17.4(1.3)$ & $17.2(1.3)$ & $F(4,1775)=2.4$ & $F(4,2118)=2.5^{*}$ \\
\hline Education attainment & & & & $23.8^{* *}$ & 2.9 \\
\hline No education & 2.7 & 3.2 & 2 & & \\
\hline Primary & 44.2 & 45.7 & 41.8 & & \\
\hline Secondary & 53.2 & 51.1 & 56.3 & & \\
\hline Household wealth & & & & $38.4^{* * *}$ & 0.07 \\
\hline Poor & 33.8 & 34.1 & 33.4 & & \\
\hline Middle & 26.1 & 27.6 & 24 & & \\
\hline Rich & 40.1 & 38.4 & 42.7 & & \\
\hline Residence type & & & & $12.9^{* * *}$ & 1.4 \\
\hline Urban & 37.7 & 35.6 & 40.9 & & \\
\hline Rural & 62.3 & 64.4 & 59.1 & & \\
\hline Relationship with lastsexual partner & & & & 1.1 & $22.2^{* *}$ \\
\hline Committed & 93.5 & 90.6 & 97.8 & & \\
\hline Non-committed & 6.5 & 9.4 & 2.2 & & \\
\hline Age of last sexual partner & & & & $22.3^{* * *}$ & $25.9^{* *}$ \\
\hline $10-14$ & 8.6 & 14.4 & - & & \\
\hline $15-19$ & 56.4 & 73.4 & 31.3 & & \\
\hline $20-25$ & 21.1 & 2.7 & 48.2 & & \\
\hline 26 and Over & 13.9 & 9.5 & 20.5 & & \\
\hline Know condom source & & & & $24.2^{* *}$ & 3.3 \\
\hline Yes & 92.6 & 96.3 & 86.9 & & \\
\hline No & 7.4 & 3.7 & 13.1 & & \\
\hline Wife beating justified & & & & $14.5^{* *}$ & 2.4 \\
\hline Yes & 50.3 & 48.9 & 52.5 & & $4.67^{*}$ \\
\hline No & 49.7 & 51.1 & 47.5 & & \\
\hline History of sexual abuse (select girls only; $n=401$ ) & & & & 0.04 & $11.6^{* *}$ \\
\hline Yes & & & 11.7 & & \\
\hline No & & & 88.3 & & \\
\hline Multiple sexual partners & & & & & \\
\hline Yes & 13.8 & 18.8 & 6 & & \\
\hline No & 86.2 & 81.2 & 94 & & \\
\hline Condom use & & & & & \\
\hline Yes & 40.8 & 41.8 & 39.3 & & \\
\hline No & 59.2 & 58.2 & 60.7 & & \\
\hline
\end{tabular}

Note: Chi-square test results indicate bivariate associations for the overall sample.

** $\mathrm{p}<.01$.

$* \mathrm{p}<.05$.

males, about $23 \%$ of males compared to $7 \%$ of females $(\mathrm{p}<.01)$. There were no statistically significant differences in condom use by gender. However, compared to males (3\%), a higher percentage of female adolescents $(13 \%)$ reported not knowing where to access condoms $(\mathrm{p}<.01)$. We also found significant differences in education levels by gender $(\mathrm{p}<.05)$, with female adolescents reporting slightly higher levels of education. Additionally, female adolescents were less likely to have sex in non-committed relationships compared to males $(\mathrm{p}<.01)$. Male adolescents (15\%) reported sexual relations with a partner 10-14 years old, while no female adolescents reported sexual relationships with a partner in this age group. However, more female adolescent reported sexual relations with much older sexual partners compared to males. These gender differences in age of most recent sexual partner were statistically significant $(\mathrm{p}<.01)$.

When examining bivariate associations of condom use and multiple sexual partnering for the overall sample, we found that all four bases of gendered power (force, resource control, consensual ideologies and social obligation) were significantly associated with sexual behaviors ( $p<.01$ ). Age, gender, household wealth, rural/urban residence, and age of sexual partner, were also significantly associated with sexual behaviors at the bivariate level $(\mathrm{p}<.05)$.

\subsection{Condom use}

Table 2 shows results of the logistic regression models examining the odds ratio of condom use among Zambia adolescents. Results for the overall sample model showed that resource control (education levels and condom access), consensual ideologies (wife beating justified), gender, household wealth, and age of sexual partner were significant predictors of condom use. Adolescents with no education $(\mathrm{OR}=0.47$, $\mathrm{p}<.05)$ and those with primary education (OR $=0.73, \mathrm{p}<.01)$ had decreased odds of condom use compared to their secondary level counterparts. Education was also significant in the male only model $(\mathrm{p}<.05)$ but not for females.

Compared to adolescents that did not know any source to obtain a condom, adolescents that had access to condoms were nearly 3 times more likely to use a condom in the overall model $(\mathrm{OR}=2.49$, $\mathrm{p}<.01$ ), and 5 times more likely to use condoms for male adolescents $(\mathrm{OR}=5.08, \mathrm{p}<.01)$. Among females only, adolescents with access to condoms were 2 times more likely to use condoms ( $\mathrm{OR}=2.21$, $\mathrm{p}<.01)$. However, when sexual abuse was added to the female only model (see Table 2), condom access was no longer significant.

In regards to consensual ideologies, adolescents that did not endorse ideologies that justify wife beating showed a $28 \%$ increase in the odds of condom use in the overall model ( $\mathrm{OR}=1.28, \mathrm{p}<.05$ ), and about a $40 \%$ increase in condom use for the male only model $(\mathrm{OR}=1.40$, 
Table 2

Predictors of condom use among adolescents.

\begin{tabular}{|c|c|c|c|c|c|c|c|c|}
\hline \multirow[b]{2}{*}{ Variable } & \multicolumn{2}{|c|}{ Overall $=1908$} & \multicolumn{2}{|c|}{ Male $=1124$} & \multicolumn{2}{|c|}{ Female $=784$} & \multicolumn{2}{|c|}{ Female $=380$} \\
\hline & OR & SE & OR & SE & OR & SE & OR & SE \\
\hline Gender (female) & $1.43^{*}$ & 0.14 & & & & & & \\
\hline Age & 1.08 & 0.04 & 1.09 & 0.06 & 1.01 & 0.07 & 0.92 & 0.10 \\
\hline \multicolumn{9}{|l|}{ Education } \\
\hline No education & $0.47^{*}$ & 0.35 & $0.41^{*}$ & 0.42 & 0.60 & 0.64 & 0.97 & 0.93 \\
\hline Primary & $0.73^{* *}$ & 0.12 & $0.62^{* *}$ & 0.15 & 0.85 & 019 & 094 & 0.27 \\
\hline Secondary education & - & - & - & - & - & - & - & - \\
\hline \multicolumn{9}{|l|}{ Household wealth } \\
\hline Rich & $1.77^{* *}$ & 0.17 & $1.73^{*}$ & 0.23 & $1.98^{*}$ & 0.28 & $2.83^{*}$ & 0.41 \\
\hline Middle & 1.16 & 0.14 & 1.03 & 0.18 & 1.31 & 0.24 & 1.13 & 0.35 \\
\hline Low & - & - & - & - & - & - & - & - \\
\hline Condom source known (Yes) & $2.49^{* * *}$ & 0.23 & $5.08^{* *}$ & 0.57 & $2.21^{* *}$ & 0.27 & 2.02 & 0.39 \\
\hline Residence type (Rural) & 1.08 & 0.15 & 1.29 & 0.21 & 0.87 & 0.24 & 1.07 & 0.36 \\
\hline Last sexual partner relationship (Committed) & 1.17 & 0.21 & 1.30 & 0.23 & 0.70 & 0.57 & 0.42 & 0.78 \\
\hline \multicolumn{9}{|l|}{ Age of last sexual partner } \\
\hline $10-14$ & 0.87 & 0.20 & 0.89 & 0.21 & & & & \\
\hline $15-19$ & - & - & - & - & - & - & - & - \\
\hline $20-25$ & $0.44^{* * *}$ & 0.17 & $0.34^{*}$ & 0.46 & $0.45^{* *}$ & 0.22 & $0.49^{*}$ & 0.32 \\
\hline 26 and Over & $0.72^{*}$ & 0.17 & 0.76 & 0.25 & 0.66 & 0.25 & $0.44^{*}$ & 0.38 \\
\hline Wife beating justified (No) & $1.28^{*}$ & 0.11 & $1.40^{*}$ & 0.14 & 1.21 & 0.17 & 1.21 & 0.26 \\
\hline Sexual abuse (Yes) & - & - & - & - & - & - & 0.89 & 0.39 \\
\hline Pseudo $\mathrm{R}^{2}$ & 0.09 & & 0.10 & & 0.11 & & 0.13 & \\
\hline$\chi^{2}$ & $117.1^{* * *}$ & & $83.5^{* *}$ & & $59.5^{* *}$ & & $31.7^{*}$ & \\
\hline
\end{tabular}

Note: All analyses are weighted. Models controlled for Zambian provinces.

** $\mathrm{p}<.01$.

$* \mathrm{p}<.05$

$\mathrm{p}<$.05), compared to adolescents that endorsed wife beating. Social obligations (sexual partner relationship commitment) and force (sexual abuse) did not emerge as significant predictors of condom use in the models.

Further, we found that adolescents from rich households showed a $77 \%$ increase in the odds of condom use in the overall model $(\mathrm{OR}=1.77, \mathrm{p}<.01)$. Household wealth remained a significant predictor of condom use in the male only model $(\mathrm{OR}=1.73, \mathrm{p}<.05)$ and in the female only model $(\mathrm{OR}=2.83, \mathrm{p}<.05)$. Female adolescents also showed a $43 \%$ increase in the odds of condom use at their last sexual encounter compared to male adolescents $(\mathrm{OR}=1.43$, $\mathrm{p}<.05)$. Results also showed that compared to having a partner in the 15-19 age group, having older sexual partners was associated with lower odds of condom use in the overall model ( $\mathrm{p}<.05)$. Age of sexual partner remained a significant predictor of condom use in the gendered models $(\mathrm{p}<.05)$.

\subsection{Multiple sexual partnering}

Table 3 shows results of the logistic regression models examining the odds ratio of multiple sexual partnering among Zambia adolescents. The overall model shows gender, relationship commitment to last sexual partner, and age of last sexual partner to have significant effects on multiple sexual partnering net of controls. Being female was associated with a $76 \%$ decrease in the odds of multiple sexual partnering $(\mathrm{OR}=0.24, \mathrm{p}<.01)$. Adolescents who were in a committed relationship with their last sexual partner were less likely to have multiple sexual partners $(\mathrm{OR}=0.51, \mathrm{p}<.01)$. This finding remained consistent in the male only model $(\mathrm{OR}=0.51, \mathrm{p}<.01)$ and the female only model ( $\mathrm{OR}=0.23, \mathrm{p}<.05)$. However, relationship commitment was no longer significant in the female only model (seen in Table 3) when sexual abuse was added to the model.

Additionally among females only, we found that girls from rich households showed greater odds of having multiple sexual partners in the past 12 months compared to those from poor households $(\mathrm{OR}=3.13, \mathrm{p}<.05)$ in the model not controlled for sexual abuse. Wealth was no longer significant when sexual abuse was added to the model (see Table 3). Additionally, we found that adolescent females who had experienced forced sex were 5 times more likely to have multiple sexual partners ( $O R=5.07, \mathrm{p}<.01$ ). Further, we found higher odds of multiple sexual partnering for female adolescents with no education compared to those with secondary level education $(\mathrm{p}<.05)$.

Compared to adolescents with sexual partners in the 15-19 age range, we found lower odds of multiple sexual partnering for adolescents with sexual partners in the $10-14$ age range $(O R=0.58$, $\mathrm{p}<.05)$ and higher odds of multiple sexual partnering for adolescents with sexual partners aged 26 and above (OR $=1.74, \mathrm{p}<.01$ ). Age of sexual partner remained a significant predictor of multiple sexual partnering in the male only model $(\mathrm{OR}=0.57, \mathrm{p}<.05)$ but not in the female only model. Additionally, we found no significant effects of consensual ideologies and condom access on the odds of multiple sexual partnering in any of the models.

\section{Discussion}

This study indicates that the four bases of gendered power, derived from social dominance theory, are applicable in understanding correlates of condom use and multiple sexual partnering among Zambian adolescents. We found condom use at about $41 \%$ in our sample, similar to previous reports among a comparable group of Zambian adolescents (Doyle et al., 2012). In concert with the our first hypothesis and social dominance theory, we found that having experienced forced sex exacerbated hiv risk sexual behaviors among adolescent females. These findings reinforce results in previous studies (Cluver et al., 2016; MYSCD et al., 2018; Slonim-Nevo \& Mukuka, 2007). In this sample, we found that about $12 \%$ of girls reported history of sexual abuse, which was strongly associated with multiple sexual partnering. The first base of gendered power, force, suggests that the power inequities inherent in women's experience of sexual abuse undermines their ability to negotiate safe sex and increases instances of risk within themselves (Pratto \& Walker, 2004; Rosenthal \& Levy, 2010). Thus these findings point to important considerations of psychosocial pathways to hiv risk behaviors. While we did not assess the effects of sexual abuse on adolescent 
Table 3

Predictors of multiple sexual partnering among adolescents.

\begin{tabular}{|c|c|c|c|c|c|c|c|c|}
\hline \multirow[b]{2}{*}{ Variable } & \multicolumn{2}{|c|}{ Overall $=1908$} & \multicolumn{2}{|c|}{ Male $=1124$} & \multicolumn{2}{|c|}{ Female $=784$} & \multicolumn{2}{|c|}{ Female $=380$} \\
\hline & OR & SE & OR & SE & OR & SE & OR & $\mathrm{SE}$ \\
\hline Gender (female) & $0.24^{* *}$ & 0.22 & & & & & & \\
\hline Age & 1.02 & 0.06 & 1.06 & 0.06 & 0.83 & 0.13 & 1.06 & 0.20 \\
\hline \multicolumn{9}{|l|}{ Education } \\
\hline No education & 1.33 & 0.38 & 0.94 & 0.44 & $8.15^{* *}$ & 0.81 & $13.05^{*}$ & 1.17 \\
\hline Primary & 0.95 & 0.16 & 0.94 & 0.17 & 0.84 & 0.39 & 0.48 & 0.61 \\
\hline Secondary education & - & - & - & - & - & - & - & - \\
\hline \multicolumn{9}{|l|}{ Household wealth } \\
\hline Rich & 1.32 & 0.22 & 1.12 & 0.24 & $3.13^{*}$ & 0.55 & 2.84 & 0.88 \\
\hline Middle & 1.07 & 0.18 & 0.95 & 0.20 & 1.67 & 0.50 & 4.62 & 0.83 \\
\hline Low & - & - & - & - & - & - & - & - \\
\hline Condom source known (Yes) & 1.09 & 0.32 & 1.12 & 0.45 & 1.21 & 0.49 & 1.95 & 0.83 \\
\hline Residence type (Rural) & 1.06 & 0.21 & 1.00 & 0.24 & 1.34 & 0.45 & 0.93 & 0.69 \\
\hline Last sexual partner relationship (Committed) & $0.51^{* *}$ & 0.23 & $0.51^{* * *}$ & 0.24 & $0.23^{*}$ & 0.71 & 0.50 & 1.30 \\
\hline \multicolumn{9}{|l|}{ Age of last sexual partner } \\
\hline $10-14$ & $0.58^{*}$ & 0.26 & $0.57^{*}$ & 0.27 & & & & \\
\hline $15-19$ & - & - & - & - & - & - & - & - \\
\hline $20-25$ & 1.11 & 0.27 & 0.92 & 0.47 & 1.54 & 0.45 & 0.48 & 0.71 \\
\hline 26 and Over & $1.74^{* * *}$ & 0.21 & 1.56 & 0.26 & 1.84 & 0.47 & 2.03 & 0.69 \\
\hline Wife beating justified (No) & 0.85 & 0.14 & 0.79 & 0.16 & 1.48 & 0.33 & 1.29 & 0.53 \\
\hline Sexual abuse (Yes) & - & - & - & - & - & - & $5.07^{* *}$ & 0.56 \\
\hline Pseudo $\mathrm{R}^{2}$ & 0.12 & & 0.05 & & 0.16 & & 0.25 & \\
\hline$\chi^{2}$ & $124.6^{* *}$ & & $34.5^{*}$ & & $46.1^{* *}$ & & $34.8^{*}$ & \\
\hline
\end{tabular}

Note: All analyses are weighted. Models controlled for Zambian provinces.

** $\mathrm{p}<.01$.

$* \mathrm{p}<.05$.

males in this study, it is likely that it would have negative implications on hiv risk behaviors as evidenced in previous studies (Cluver et al., 2016; MYSCD et al., 2018). Further investigation is needed to explore gendered variations in effects of sexual abuse and mechanisms through which sexual abuse history impacts sexual behavior.

The link between economic disadvantage and sexual risk was supported in our study, per our second hypothesis, and has been well established (Butts et al., 2017; Butts et al., 2018; Cluver et al., 2016; Gyimah et al., 2014; Jukes et al., 2008; Madise et al., 2007; Muzyamba et al., 2015; Ranganathan et al., 2016; Wamoyi et al., 2014). Social dominance theory posits negative health outcomes for groups with limited access to resources. Low levels of education, limited access to condoms and poverty acted as a barrier to condom use, and for females only, having no education exacerbated risk for multiple sexual partnering. We found evidence of discriminatory resource distribution by gender as posited by the second base of gendered power, resource control. They were disproportionally more females than males that lacked information on where to access condoms as supported by other studies (Butts et al., 2018; Central Statistical Office (CSO) [Zambia], Ministry of Health (MOH) [Zambia], and ICF International, 2014). This places females at higher risk for adverse health outcomes given that condom access was the strongest predictor of condom use among adolescents in our study. Negative societal norms that stigmatize and discourage women's active role in their sexual health (e.g. condom seeking and condom use initiation) may facilitate this discrepancy (Burgard \& Kusunoki, 2009; Butts et al., 2017; Joffe \& Bettega, 2003).

Additionally, we found slightly higher levels of education among female than male adolescents in support of recent studies that show an emerging female advantage in educational enrollment and attainment in low-income countries (Saasa et al., 2018; Grant \& Behrman, 2010; Psaki, McCarthy, \& Mensch, 2018). It is important to note however, that education failed to buffer adolescent females against unprotected sex while it proved protective for male adolescents in our study. This may suggest that even with the appearance of gender parity in education attainment, other factors such as gender variant learning outcomes (Grant \& Behrman, 2010) or limited sexual decision making power (Magnani et al., 2002) may facilitate the female disadvantage in condom use. Further research should examine the gender variant mechanisms through which education interrelates with sexual risk behaviors among adolescents.

Contrary to our third hypothesis and the findings of others (Burgard \& Kusunoki, 2009; Hendriksen et al., 2007), relationship commitment levels did not have significant impact on condom use. While we found relationship commitment to safeguard adolescents from multiple sexual partnering, the lack of effect on condom use is concerning. This implies common occurrence of unprotected sex regardless of whether sex is casual or with a boyfriend or girlfriend. Thus when HIV infection penetrates adolescents' social networks, risk of infection is high. However, it is important to note that the lack of significant and gender variant effects of social obligations on condom use maybe due to the small sample size of adolescents in our study who were not in a committed relationship with their last sexual partner (about 7\%). Further research with a large enough sample is needed to determine whether the female disadvantage in HIV risk is facilitated by social obligations among Zambian adolescents.

Interestingly, slightly more adolescent girls than boys in the sample held beliefs about the justification of wife beating under certain conditions, suggesting that perceptions about abuse of women is internalized by both genders. As explained by social dominance theory, the socialization and cultural transmission effects of societal norms and values that maintain the subordinate position of women can influence the use of violence against women (Pratto \& Walker, 2004). Adolescents from poor backgrounds, limited education and rural areas were more likely to endorse wife beating. In support of our fourth hypothesis, these ideologies were associated with lower condom use among male adolescents, which potentially perpetuates the disadvantaged position of females in condom use negotiation in heterosexual relationships. These findings support other sub-Saharan African studies that found genderunequal norms to be associated with lack of condom use and other forms of contraceptives (Svanemyr, 2019; Tsai \& Subramanian, 2012). Interventions aimed at modifying gender-unequal norms and beliefs in efforts to reduce HIV risk among adolescents are needed. Further research can also examine effects of consensual ideologies on intimate partner violence among adolescents and other health related outcomes. 
Other notable findings in our study included negative effects of age disparate relationships on sexual risk behavior similar to previous studies (Butts et al., 2017; Doyle et al., 2012). Condom use varied significantly by age of sexual partner where relationship power dynamics could make it difficult for younger partners to negotiate condom use. Additionally. the number of adolescent males who had sex with very young girls (14\%) is concerning given that some children in the 10-14 age group might not have the developmental capacity to consent to sex and let alone negotiate condom use. This finding may suggest greater risk among younger girls for non-consensual sex from adolescent partners. Efforts that promote the protection of vulnerable children as well as youth friendly education programs about sexual health behaviors are recommended.

\section{Limitations}

Limitations that warrant cautious interpretation of the findings in this study should be acknowledged. The use of cross-sectional data does not allow for causal inferences between our predictor and outcome variables, or examine changes in sexual behavior over time. The utilization of a secondary data set and consequent proxy variables entail a lack of information collected to specifically meet the aims of this study. This warrants cautious interpretations of the findings. Future research should collect primary data in order to get a holistic understanding of gender-based power and adolescent HIV risk. The limited variability in our social obligations variable may have weakened our ability to derive meaningful findings on the effects of relationship commitment levels on sexual risk behaviors. Additionally, the wide range in number of past year sexual partners in the sample, may speak to differences in adolescent and partner characteristics that our study does not capture. Future research should consider the broader underlying forces and other factors that lead to adolescent multiple sexual partnering. Lastly, our data had a significant amount of cases missing on the dependent variables, which greatly reduced the sample size in our study. Despite the limitations, we still had a large enough sample in our analyses to draw meaningful conclusions that are consistent with the literature. Additionally, the use of sample weights allowed for results to be representative at the national level.

\section{Implications}

The current study has a number of important implications. These include the need for enforcement of laws that protect young people from sexual violence, increased support toward condom access and challenging discriminatory resource distribution mechanisms and other underlying factors that disadvantage females. The continued low utility of condoms calls for further assessment of factors that impede condom use among adolescents and strategies that promote safe sex for sexually active teenagers. Intervention efforts aimed at empowering female adolescents can help facilitate greater sexual decision-making power. For instance, the 'DREAMS' Partnership, an ongoing intervention in several African countries, including Zambia is a multilevel approach aimed to reduce hiv risk and advance gender equality among adolescent girls and young women. Findings are promising and show significant declines (25-40\%) in new HIV infections among adolescent girls and young women in most DREAMS intervention regions (Chimbindi et al., 2018; PEPFAR, 2018).

To enhance adolescents' ability to engage in HIV-risk reducing behaviors, a cultural shift in values and beliefs that place women in subordinate positions is needed. While difficulties in changing cultural norms have been acknowledged (Jukes et al., 2008), young people whose beliefs and values are not yet entrenched maybe more receptive to change. The development and implementation of multilevel interventions that address structural and cultural barriers to advancing women's social status should be supported among Zambian adolescents as these have shown to mitigate HIV-related risk (Butts et al., 2017;
Jewkes et al., 2008; Kyegombe et al., 2014; Remme et al., 2014). For example, a cluster randomized control trial conducted among 15-26 year olds in South Africa found that an HIV prevention program that also addressed gender -unequal norms significantly reduced hiv risk behaviors among young men (Jewkes et al., 2008). As Jukes et al. (2008) points out, effective tackling of gender-based HIV risk will require both males and females to change alongside each other in beliefs and behaviors.

Additionally, government agencies, NGOs and policy makers should attend to poverty alleviation strategies and the provision of income generating alternatives for adolescents whose HIV risk is likely driven by structural deprivations. Evidence shows that structural interventions such as cash transfers or scholarship programs have been found to reduce risky sexual behaviors, attenuate the negative effects of sexual abuse on sexual risk behaviors and improve educational outcomes among sub-Saharan African adolescents (Cluver et al., 2013, 2016; Hallfors et al., 2011; Pettifor, MacPhail, Nguyen, \& Rosenberg, 2012). Advantages of increasing adolescents' resources, such as education, include increased likelihood of challenging ideologies that promote gender inequality as education levels advance (Jukes et al., 2008; Rosenthal \& Levy, 2010).

Future research can examine sexuality among adolescents from a longitudinal perspective to establish whether sexual behavior maybe linked to changes in gendered power across the lifespan, An examination of potential moderators of the negative effects of gendered power on HIV risk is also warranted.

\section{Conclusions}

This study contributes to the current literature on adolescent HIVrisk sexual behaviors and highlights mechanisms through which disproportionate HIV risk among adolescent females maybe facilitated and maintained. Our findings show structural drivers (living in poverty, low levels of education, limited access to condoms), psychosocial problems (sexual abuse) and social norms (beliefs and values that place women in subordinate positions relative to men) to influence adolescent HIV risks in Zambia. The commonality of sexual activity among adolescents and its potential for serious consequences on the life course calls for interventions that consider how different facets of power shape adolescent HIV risk. Special attention should be given to interventions that improve women's social standing and the development of social protections that can mitigate structural drivers that increase adolescent risk for HIV infection by virtue of their socio-economic conditions and gender.

\section{Declaration of Competing Interest}

The authors have no conflicts of interest to report.

\section{References}

Amoateng, A. Y., Kalule-Sabiti, I., \& Arkaah, Y. J. (2014). The effect of socio-demographic factors on risky-sexual behaviours of adolescents in the North West Province of South Africa. African Population Studies, 28(1), 487-498. https://doi.org/10.11564/28-1502.

Birdthistle, I., Floyd, S., Nyagadza, A., Mudziwapasi, N., Gregson, S., \& Glynn, J. R. (2009). Is education the link between orphanhood and HIV/HSV-2 risk among female adolescents in urban Zimbabwe? Social Science \& Medicine, 68(10), 1810-1818.

Burgard, S., \& Kusunoki, Y. (2009). Gender and condom use among black South African young people. Population Studies Center, University of Michigan.

Butts, S. A., Kayukwa, A., Langlie, J., Rodriguez, V. J., Alcaide, M. L., Chitalu, N., .. Jones, D. L. (2018). HIV knowledge and risk among Zambian adolescent and younger adolescent girls: challenges and solutions. Sex Education, 18(1), 1-13.

Butts, S. A., Parmley, L. E., Alcaide, M. L., Rodriguez, V. J., Kayukwa, A., Chitalu, N., .. Jones, D. L. (2017). Let us fight and support one another: Adolescent girls and young women on contributors and solutions to HIV risk in Zambia. International Journal of Women's Health, 9, 727-737.

Central Statistical Office (CSO) [Zambia], Ministry of Health (MOH) [Zambia], and ICF International (2014). Zambia Demographic and Health Survey 2013-14. Rockville, Maryland, USA: Central Statistical Office, Ministry of Health, and ICF International. 
Chanda-Kapata, P., Klinkenberg, E., Maddox, N., Ngosa, W., \& Kapata, N. (2016). The prevalence and socio-economic determinants of HIV among teenagers aged 15-18 years who were participating in a mobile testing population-based survey in 20132014 in Zambia. BMC Public Health, 16(1), 1-7. https://doi.org/10.1186/s12889016-3449-3.

Chimbindi, N., Birdthistle, I., Shahmanesh, M., Osindo, J., Mushati, P., Ondeng'e, K., .. Busza, J. (2018). Translating DREAMS into practice: Early lessons from implementation in six settings. PLoS One, 13(12), e0208243.

Clark, S., Bruce, J., \& Dude, A. (2006). Protecting young women from HIV/AIDS: the case against child and adolescent marriage. International Family Planning Perspectives, 79-88.

Cluver, L., Boyes, M., Orkin, M., Pantelic, M., Molwena, T., \& Sherr, L. (2013). Childfocused state cash transfers and adolescent risk of HIV infection in South Africa: A propensity-score-matched case-control study. The Lancet Global Health, 1(6), e362-e370.

Cluver, L. D., Orkin, F. M., Meinck, F., Boyes, M. E., \& Sherr, L. (2016). Structural drivers and social protection: Mechanisms of HIV risk and HIV prevention for south African adolescents. Journal of the International AIDS Society, 19(1), 20646.

Conroy, A. A. (2015). The influence of relationship power dynamics on HIV testing in rural Malawi. The Journal of Sex Research, 52(3), 347-359.

Croft, T. N., Marshall, A. M., \& Allen, C. K. (2018). Guide to DHS statistics. Rockville, Maryland, USA: ICF.

Doyle, A. M., Mavedzenge, S. N., Plummer, M. L., \& Ross, D. A. (2012). The sexual behaviour of adolescents in sub-Saharan Africa: Patterns and trends from national surveys. Tropical Medicine \& International Health, 17(7), 796-807. https://doi.org/10. 1111/j.1365-3156.2012.03005.x.

Fleischman, J., \& Peck, K. (2015). Addressing HIV risk in adolescent girls and young women. CSIS Global Health Policy Center. Retrieved on August 8, 2018 from https:// www.csis.org/analysis/addressing-hiv-risk-adolescent-girls-and-youngwomenhttps://janetfleischman.com/wp-content/uploads/2015/04/Addressing-HIVRisk-in-Adolescent-Girls-April-2015.pdf.

Grant, M. J., \& Behrman, J. R. (2010). Gender gaps in educational attainment in less developed countries. Population and Development Review, 36(1), 71-89.

Gyimah, S., Kodzi, I., Emina, J., Adjei, J., \& Ezeh, A. (2014). Adolescent sexual risk-taking in the informal settlements of Nairobi, Kenya: Understanding the contributions of religion. Journal of Religion and Health, 53(1), 13-26.

Hallfors, D., Cho, H., Rusakaniko, S., Iritani, B., Mapfumo, J., \& Halpern, C. (2011). Supporting adolescent orphan girls to stay in school as HIV risk prevention: Evidence from a randomized controlled trial in Zimbabwe. American Journal of Public Health, 101(6), 1082-1088.

Hargreaves, J., Morison, L., Kim, J., Bonell, C., Porter, J., Watts, C., ... Pronyk, P. (2008). The association between school attendance, HIV infection and sexual behaviour among young people in rural South Africa. Journal of Epidemiology and Community Health, 62(2), 113-119.

Hendriksen, E. S., Pettifor, A., Lee, S. J., Coates, T. J., \& Rees, H. V. (2007). Predictors of condom use among young adults in South Africa: The reproductive health and HIV research unit national youth survey. American Journal of Public Health, 97(7), 1241-1248.

Hirsch, J. S., Wardlow, H., \& Smith, D. J. (2009). The secret: Love, marriage, and HIV. Vanderbilt University Press.

Jewkes, R., Dunkle, K., Nduna, M., \& Shai, N. J. (2012). Transactional sex and HIV incidence in a cohort of young women in the stepping stones trial. Journal of AIDS and Clinical Research, 3(5), 158.Doi: https://doi.org/10.4172/2155-6113.1000158

Jewkes, R., Nduna, M., Levin, J., Jama, N., Dunkle, K., Puren, A., \& Duvvury, N. (2008). Impact of stepping stones on incidence of HIV and HSV-2 and sexual behaviour in rural South Africa: Cluster randomised controlled trial. Bmj, 337, a506.

Jewkes, R. K., Dunkle, K., Nduna, M., Jama, P. N., \& Puren, A. (2010). Associations between childhood adversity and depression, substance abuse and HIV and HSV2 incident infections in rural south African youth. Child Abuse \& Neglect, 34(11), 833-841.

Joffe, H. L. N., \& Bettega, N. (2003). Social representation of AIDS among Zambian adolescents. Journal of Health Psychology, 8(5), 616-631.

John, C., Okolo, S. N., \& Isichei, C. (2014). Sexual risk behavior and HIV infection among adolescents in secondary schools in Jos, Nigeria. Nigerian Journal of Paediatrics, 41(2), 86-89.

Jukes, M., Simmons, S., \& Bundy, D. (2008). Education and vulnerability: The role of schools in protecting young women and girls from HIV in southern Africa. Aids, 22, S41-S56.

Kyegombe, N., Abramsky, T., Devries, K. M., Starmann, E., Michau, L., Nakuti, J., .. Watts, C. (2014). The impact of SASA! A community mobilization intervention, on reported HIV-related risk behaviours and relationship dynamics in Kampala, Uganda Journal of the International AIDS Society, 17(1), 19232.

Lightfoot, E., Maree, M., \& Ananias, J. (2009). Exploring the relationship between HIV and alcohol use in a remote Namibian mining community. African Journal of AIDS Research, 8(3), 321-327.

Luke, N. (2005). Confronting the 'sugar daddy' stereotype: Age and economic asymmetries and risky sexual behavior in urban Kenya. International Family Planning Perspectives, 6-14.

Madise, N., Zulu, E., \& Ciera, J. (2007). Is poverty a driver for risky sexual behaviour? Evidence from national surveys of adolescents in four African countries. African Journal of Reproductive Health, 11(3), 83-98.
Magadi, M. A., \& Uchudi, J. (2015). Onset of sexual activity among adolescents in HIV/ AIDS-affected households in Sub-Saharan Africa. Journal of Biosocial Science, 47(02), 238-257.

Magnani, R., Karim, A., Weiss, L., Bond, K., Lemba, M., \& Morgan, G. (2002) Reproductive health risk and protective factors among youth in Lusaka, Zambia. Journal of Adolescent Health, 30(1), 76-86.

Ministry of Youth Sport and Child Development (2018). Ministry of Community Development and Social Services, University of Zambia, United Nations Children's Fund, Save the Children International, United States Centers for Disease Control and Prevention. Violence against Children in Zambia: Findings from a national survey, 2014. Lusaka: Ministry of Youth, Sport and Child Development. Retrieved from: https://www. unicef.org/zambia/media/1091/file/Zambia-VAC-study-2018.pdf.

Muzyamba, C., Broaddus, E., \& Campbell, C. (2015). You cannot eat rights: A qualitative study of views by Zambian HIV-vulnerable women, youth and MSM on human rights as public health tools. BMC International Health and Human Rights, 15(1), 26.

Operario, D., Underhill, K., Chuong, C., \& Cluver, L. (2011). HIV infection and sexual risk behaviour among youth who have experienced orphanhood: Systematic review and meta-analysis. Journal of the International AIDS Society, 14, 25.

Ott, M. Q., Barnighausen, T., Tanser, F., Lurie, M. N., \& Newell, M. L. (2011). Age-gaps in sexual partnerships: Seeing beyond 'sugar daddies'. AIDS (London, England), 25(6), 861.

PEPFAR (2018). Dreams report: Dreaming of an AIDS-free future. Retrieved on august, 21, 2019 from https://www.pepfar.gov/documents/organization/287807.pdf.

Pettifor, A., MacPhail, C., Nguyen, N., \& Rosenberg, M. (2012). Can money prevent the spread of HIV? A review of cash payments for HIV prevention. AIDS and Behavior, 16(7), 1729-1738.

Pratto, F., \& Walker, A. (2004). The bases of gendered power. In A. H. Eagly, A. E. Beall, \& R. J. Sternberg (Eds.). The psychology of gender (pp. 242-268). (2nd ed.). New York: Guilford.

Psaki, S. R., McCarthy, J., \& Mensch, B. S. (2018). Measuring gender equality in education: Lessons from trends in 43 countries. Population and Development Review, 44(1), 117-142. https://doi.org/10.1111/padr.12121.

Pulerwitz, J., Gortmaker, S. L., \& DeJong, W. (2000). Measuring sexual relationship power in HIV/STD research. Sex Roles, 42(7-8), 637-660.

Ranganathan, M., Heise, L., Pettifor, A., Silverwood, R. J., Selin, A., MacPhail, C., .. Piwowar-Manning, E. (2016). Transactional sex among young women in rural South Africa: Prevalence, mediators and association with HIV infection. Journal of the International AIDS Society, 19(1), 20749.

Remme, M., Siapka, M., Vassall, A., Heise, L., Jacobi, J., Ahumada, C., ... Watts, C. (2014). The cost and cost-effectiveness of gender-responsive interventions for HIV: A systematic review. Journal of the International AIDS Society, 17(1), 19228.

Rosenthal, L., \& Levy, S. R. (2010). Understanding women's risk for HIV infection using social dominance theory and the four bases of gendered power. Psychology of Women Quarterly, 34(1), 21-35.

Saasa, S. K., Choi, Y. J., \& Nackerud, L. (2018). Barriers to safe-sex behavior change in Zambia: Perspectives from HIV/AIDS psychosocial counselors. Journal of HIV/AIDS \& Social Services, 17(4), 274-289.

Sidanius, J., \& Pratto, F. (1999). Social dominance: An intergroup theory of social hierarchy and oppression. New York: Cambridge University Press.

Sidanius, J., Pratto, F., van Laar, C., \& Levin, S. (2004). Social dominance theory: Its agenda and method. Political Psy-chology, 25, 845-880.

Slonim-Nevo, V., \& Mukuka, L. (2007). Child abuse and AIDS-related knowledge, attitudes and behavior among adolescents in Zambia. Child Abuse \& Neglect, 31(2), 143-159.

Smith, D. J. (2007). Modern marriage, men's extramarital sex, and HIV risk in southeastern Nigeria. American Journal of Public Health, 97(6), 997-1005.

Stephenson, R. (2009). Community influences on young people's sexual behavior in 3 African countries. American Journal of Public Health, 99(1), 102-109.

Svanemyr, J. (2019). Adolescent pregnancy and social norms in Zambia. Culture, Health \& Sexuality, 1-15.

Toska, E., Pantelic, M., Meinck, F., Keck, K., Haghighat, R., \& Cluver, L. (2017). Sex in the shadow of HIV: A systematic review of prevalence, risk factors, and interventions to reduce sexual risk-taking among HIV-positive adolescents and youth in sub-Saharan Africa. PLoS One, 12(6), e0178106.

Tsai, A. C., \& Subramanian, S. V. (2012). Proximate context of gender-unequal norms and women's HIV risk in sub-Saharan Africa. AIDS (London, England), 26(3), 381-386.

UNAIDS (2019). Country factsheets: Zambia. Retrieved on August 8, 2019 from https:// www.unaids.org/en/regionscountries/countries/zambia.

UNICEF (2019). HIV/AIDS: Adolescents. Retrieved on September 21, 2018 from https:// data.unicef.org/topic/adolescents/hiv-aids/.

Wamoyi, J., Mshana, G., Mongi, A., Neke, N., Kapiga, S., \& Changalucha, J. (2014). A review of interventions addressing structural drivers of adolescents' sexual and reproductive health vulnerability in sub-Saharan Africa: Implications for sexual health programming. Reproductive Health, 11(1), 88.

Wingood, G. M., \& DiClemente, R. J. (2000). Application of the theory of gender and power to examine HIV-related expo- sures, risk factors, and effective interventions for women. Health Education \& Behavior, 27, 539-565.

World Bank (2019). Zambia at a glance. [summary data]. Retrieved on august 21, 2019 from http://data.worldbank.org/country/zambia. 